\title{
A new strategy for safe diving
}

\author{
Mostafa Ali Biegi ${ }^{1, ~ *, ~ E r f a n ~ G h a s e m ~ K h a n i ~}{ }^{2}$, Tayebeh Hajjari ${ }^{3}$ \\ ${ }^{1}$ Young Researchers and Elite Club, Firoozkooh Branch, Islamic Azad University, Firoozkooh, Iran. \\ ${ }^{2}$ Department of Industrial Engineering, Faculty of Industrial and Mechanical Engineering, Qazvin Branch, Islamic Azad University, Qazvin, \\ Iran. \\ ${ }^{3}$ Department of Mathematics, Firoozkooh Branch, Islamic Azad University, Firoozkooh, Iran.
}

\section{Email address:}

mostafaalibeigi@gmail.com (M. Ali Beigi),erfanghasemkhani1@gmail.com (E. Ghasem Khani), tayebehajjari@yahoo.com (T. Hajjari)

\section{To cite this article:}

Mostafa Ali Biegi, Erfan Ghasem Khani, Tayebeh Hajjari. A New Strategy for Safe Diving. American Journal of Life Sciences. Special Issue: Recent Researches in Diving and its Relations with Mathematics. Vol. 3, No. 3-1, 2015, pp. 12-17. doi: 10.11648/j.ajls.s.2015030301.12

\begin{abstract}
Safety is one of the most important components of diving. In various diving systems, there are many different methods in case of diver missing and physical sudden problems of the divers. Based on the rapid progress of science and existing risks and problems for divers, in this paper, we present a new method for safety of divers in order to have a safe and reliable diving that is more convenient than the existing methods. In proposed method, there is a special sensor, which is put on the lower arm of diver, and it has some advantages. Finally, we discuss different cases to demonstrate the advantages of the presented method.
\end{abstract}

Keywords: Life Science, Diving, Safety of Diver, Diving Technology, Artificial Intelligence, Underwater Sensor, Professional Association of Diving Instructors (PADI)

\section{Introduction}

From the past, human were contemplating about going underwater for observation and discovery. In history, men were engaged in underwater commerce, salvage and military activities and to expand the frontiers of knowledge through exploration and research. No one knows when man first discovered he could go under water by holding his breath, but diving as a profession can be traced back to more than 5000 years.

These early divers efforts were restricted to shallow waters (less than 100 feet), with the divers collecting food, sponges, coral and pearl that were commercially valuable. One of the first records of such diving is found in the writings of the Greek historians, "Herodotus". He tells the story of a diver called Scyllis, who was working for the Persian king Xerxes to recover sunken treasure in the fifth century B.C. From the earliest times, divers were active in operations. Their mission was cutting anchor cables of enemy ships adrift, boring or hunching holes in the bottoms of enemies ship's and building harbor defenses at their harbors then attempting to destroy defense support of enemy.

Other early divers developed salvage industry focused on the major shipping ports of the eastern Mediterranean.

The most obvious and necessary means in increasing the capabilities of a diver underwater was to provide an air supply. First they used hollow reeds or tubes extending, their head to the surface. The user could remain submerged for a long time but couldn't accomplish well.

Breathing tubes were employed mainly as a tactic in military operations where they permitted an undetected approach to an enemy border, but by these tubes the divers couldn't go to deep areas.

In an Assyrian frieze ninth century B.C, a diver is shown using inflated animal skins as air tanks. This idea is very old and these men were swimmers using skins for floating. It would be impossible to submerge while holding such instrument.

In the late middle ages, a workable diving system was observed. In 1240, Roger Bacon made a reference for instruments, which men could walk on sea or river beds without any danger. In the sixteenth and seventeenth centuries, some researchers explained and published a sample of equipment which emphasized on later successful developments.

In 500 B.C. Scyllis demonstrates practical use of breath-hold diving by performing military exploits for the King of Persia.

In 1530, First diving bell is invented.

Von Guericke in 1650 develops the first effective air pump. 
With such a pump Robert Boyle is able to undertake experiments in compression and decompression of animals.

Robert Boyle in 1677, English physicist and originator of Boyle's law, observes gas bubble in eye of viper that had been compressed and then decompressed. He writes: "I have seen a very apparent bubble moving from side to side in the aqueous humor of the eye of a viper at the time when this animal seemed violently distressed in the receiver from which the air had been exhausted." This is the first recorded observation of decompression sickness or "the bends."

In1690, Edmund Halley (of comet fame) patents a diving bell which is connected by a pipe to weighted barrels of air that can be replenished from the surface. Both barrel and bell (the latter with men in it) are lowered to depth; dives to over 60 feet for 90 minutes are recorded. Diving bells are thus shown to be practicable devices. Englishman John in 1715, Lethbridge builds a "diving engine," an underwater oak cylinder that is surface-supplied with compressed air. Inside this device a diver can stay submerged for 30 minutes at 60 feet, while protruding his arms into the water for salvage work. Water is kept out of the suit by means of greased leather cuffs, which seal around the operator's arms. The diving engine is claimed to be used successfully for many years.

In 1776, First authenticated attack by military submarine American Turtle vs. HMS Eagle, New York harbor. In 1788, American John Smeaton refines diving bell; incorporates an efficient hand-operated pump to supply fresh compressed air and a non-return valve to keep air from going back up the hose when pumping stops. In 1790 Smeaton's diving bell is used at Ramsgate Harbor, England, for salvage work. In another 10 years his bell is found in all major harbors.

In 1823, Charles Anthony Deane, an English inventor, patents a "smoke helmet" for fighting fires. At some point in the next few years it is used for diving as well. The helmet fits over a man's head and is held on with weights; air is supplied from the surface through a hose. In 1828 Charles and his brother John Deane market the helmet with a "diving suit." The suit is not attached to the helmet but only secured with straps; thus the diver cannot bend over without risking drowning. Even so, the apparatus is used successfully in salvage work, including the removal of some canon from the Royal George in 1834-35. In 1825, "First workable, full-time SCUBA" is invented by an English-man, William James. It incorporates a cylindrical belt around the diver's trunk that serves as an air reservoir, at 450 psi. (It is unclear if this equipment was ever actually used for diving; see Marx 1990 and Brylske 1994 in the Bibliography). Other inventors about this time are also working on self-contained underwater breathing apparatus.

Many researches and progress in 1843 to 1936.

Le Prieur In 1936, founds the world's first SCUBA diving club, called the "Club of Divers and Underwater Life."

Edgar End and Max Nohl in 1938, make the first intentional saturation dive, spending 27 hours at a depth of 101 feet in a Milwaukee hospital hyperbaric chamber. Decompression takes five hours and one of the divers (Nohl) suffers the bends. In 1939, The first completely successful rescue of submarine-trapped men is carried out. On May 23 the USS Squalus, a new 310-foot submarine, sinks in 243 feet of water during a checkout dive in the North Atlantic. Twenty-six of the crew die instantly in the flooded aft compartments. The forward, unflooded area holds 33 men (including the captain) with enough air and water to last several days. Within hours the largest submarine rescue in history is underway. By midnight of May 25 all 33 men are rescued by a new diving bell, the McCann-Erickson Rescue Chamber. The chamber fits over an escape hatch on the submarine; when the chamber and submarine hatches are opened the men enter the bell under one atmosphere of pressure. Four separate trips are used to rescue the men. The submarine is later salvaged and renovated, and enters World War II duty as the USS Sailfish.

In 1940, First year of production of Owen Churchill's swim fins. Initially, only 946 pairs are sold, but in later years production increases substantially, and tens of thousands are sold to the Allied forces.

In 1941-1944, During World War II Italian divers, working out of midget submarines, use closed circuit scuba equipment to place explosives under British naval and merchant marine ships. Later in the war the British adopt this technology to sink German battleship Tirpitz.

In 1942-43, Jacques-Yves Cousteau (a French naval lieutenant) and Emile Gagnan (an engineer for Air Liquide, a Parisian natural gas company) work together to redesign a car regulator that will automatically provide compressed air to a diver on his slightest intake of breath. (Prior to this date, all self-contained apparatus still in use supplied air continuously, or had to be manually turned on and off. For unclear reasons, the 19th century demand regulator of Rouquayrol-Denayrouse had long been abandoned.) Cousteau and Gagnan attach their new demand valve regulator to hoses, a mouthpiece and a pair of compressed air tanks. In January 1943 Cousteau tests the unit in the cold Marne River outside Paris. After a modification (placing the intake and exhaust valves at the same level), they patent the Aqua Lung...

In 1983, The first commercially available dive computer, the Orca Edge, is introduced. In the next decade many manufacturers market dive computers, and they become common equipment among recreational divers.

In 1985, U.S.-French team headed by Woods Hole researcher Robert Ballard, using a remote controlled camera attached to the mother ship, finds the wreck of the Titanic. The ship sits broken into two sections at 12,500 feet depth, some 400 miles northeast of New York. On April fifteenth, 1912, five days into its maiden voyage, Titanic hit an iceberg and sank in less than three hours. At the time she was the largest ship in the world. A total of 1522 passengers and crew died. Since 1985 both the U.S. and France have revisited the site, and the French have recovered artifacts from the ship.

In 1993, The 50th anniversary of the invention of modern scuba diving is celebrated around the world. PADI, the largest of the national training agencies, certifies 515,000 
new divers worldwide.

1990s, An estimated 500,000 new scuba divers are certified yearly in the U.S., new scuba magazines form, dive computers proliferate, new liveaboards ply the waters and scuba travel is transformed into a big business. In North America alone recreational diving becomes a multi-billion dollar industry. At the same time there is expansion of "technical diving" Ä diving by non-professionals who use advanced technology, including mixed gases, full face masks, underwater voice communication, propulsion systems, etc.

In the following we describe some cases of diving accidents, that shows we need and Necessity have a new method for more safety in diving.

- Divers lost in bali

The body of a Japanese diver missing since February 14, 2014 has been found (3/16/2014) in the ocean south Java near Malang. The discovery of the missing Japanese, part of a group of 7 women diving near Nusa Lembongan off Bali's southeast coast, means that all members of group have been now been accounted for. 5 of divers were rescued after floating the sea for nearly three days, while a 6th diver's body washed up on the shore near Sanur Bali in the week following her disappearance.

The final missing diver has been identified by police as Shoko Takahashi. The police precinct in Malang contacted the police in Klungkung, Bali on Sunday, March 16, 2014, Bali who held the open file on the missing diver.

The body was discovered floating in the ocean near Pulau Sempu, near Malang on March 14, 2014 by local fishermen.

- Two divers' bodies found in Scapa Flow, Scotland, Thursday, June 20, 2013

Two bodies have been discovered in Scapa Flow in Scotland's Orkney Islands, 40 metres away from the wreckage of the SMS Brummer, a German war vessel scuttled during the aftermath of World War I. A Police Scotland spokesperson said the sighting, which was reportedly made by divers from the local area, was reported to the force at 10:40 BST (0940 UTC) yesterday.

The persons have yet to be formally identified, although it is thought the bodies are of two male divers from the Netherlands, who had been diving on May 28 on the remains of the ship. The failure of the divers to re-emerge above the water and the subsequent alert by the skipper of the divers' boat prompted a large-scale search of the area, which was abandoned after two days as no sighting of the divers had been reported.

A Police Scotland dive unit at Aberdeen was alerted to the scene to assist with the retrieval of the bodies from the seabed. The divers' next of kin have been told of the situation. The remains of ships such as the SMS Brummer reportedly make Scapa Flow a popular diving location.

- Six divers lost in Pulau Tioman Marine Park, June 24, 2012

Six scuba divers who went missing off Tioman resort island were rescued by a passing tugboat Sunday, a maritime official said.

The Indonesian boat saved the divers, comprising a
Singaporean, a Chinese and four Malaysians, off Tioman island on Malaysia's east coast, said an official with the Malaysian Maritime Enforcement Agency. The boat later informed Malaysian authorities, who picked up the divers.

\subsection{A Review of Training PADI System}

The Professional Association of Diving Instructors (PADI) with more than 40 years of experience was founded in 1966 by two divers of America navy named John Cronin and Ralph Erickson with the aim of diving training by new methods without military operations that was common on that period. This institution by new teaching methods and American training system and with the collaboration of many universities all over the world and using hospitability methods of hotels to give services to the tourists, attempted to design a new method in diving training and the results are the increasing development of this recreation among the modern and advanced societies and communities in the world. This institution acquired $75 \%$ of total diving training in all over the world.

Today, this institution with 5300 diving centers in 180 countries in the world and about 130,000 skillful instructors plays an important role in global tourism industry by giving safe and efficient diving activities all over the world and presented a new standard in ecotourism and above all safety motto and it is also accepted by many people in the world.

\subsection{The Advantages of PADI Training System}

- The most recognized international certificates of diving in the world

- High diversity of training aid instruments

- Training without any time limitation by considering the skill of the learner

- The widest set of specialty courses

- Receiving academic credits

All training courses of PADI from elementary to advanced are evaluated by quality control institutions in the world such as world standard organization and this institution is recognized as the only training institution of diving in the world with world standard certification. All of the training courses of PADI are evaluated in high education council of America, England, Australia, New Zealand, Japan and other European community members state and they are accepted as academic courses in the fields. Today, compatibility of PADI training courses is possible in most of the countries in the world.

- Being responsible to protect the marine environment and the like.

Each year, PADI training system evaluates its standards and in cases of any weaknesses and any changes, it is modified. In this system, there are good and scientific methods for diver safety. For example, it is not possible to dive one by one and the minimum number for diving is two people based on observing diving degree.

One method, in case of losing your buddy in diving: at first rotate as 360 degree for $1 \mathrm{~min}$ and if you didn't see any other 
diver, go to the surface of water and if no divers goes up, from the bubbles, the diver can be found and other measurements can be taken.

Some cases are of great importance in case of the missing divers and danger to their life and sudden change in the health as:

1 If two divers lose each other and one of them is faced with a danger such as being trapped in nest and other diver suddenly has heart attack, he needs help from the surface of water by the group in the boat or coast and how they are informed?

2 The above case is considered when due to the problem in diving computer and barometer due to the damage and etc or the aim in the capsule is shown by differently and air is finished.

Based on the above items, it is possible than such events are not occurred but due to protecting the life of people and logical and safe use of the healthy recreations, we need a good method to control vital signs of the diver in various conditions and safety of the diver should be considered in different coactions as missing one diver.

In this study, by a good wireless sensor, a new method is presented to achieve the above items and compared to the other common methods, increases the safety of the diver.

The present study is organized as follows:

Section II is dedicated to select a good sensor for the proposed method. Section III presents the proposed method with its advantages in the examples. The section IV is conclusion of the study.

\section{Selecting a Good Sensor}

Wireless Sensor Actor Network (WSAN)is a network with many small nodes. In each node, there are many sensors/actuators. Sense/actuator network is interacted strongly with physical environment. The information of the environment is obtained via the sensors and via the actuators, the reaction is presented. The nodes are connected by wireless. Each node works independently without the intervention of human being and it is physically very small and it has some limitations in processing, memory capacity, power source and etc. These limitations bring many problems that are the source of many research discussions in this regard. This network follows the protocol stack of traditional networks but due to the limitations and differences of application, the protocols should be re-written [9].

\subsection{The Reason of Using Wireless Sensor Networks in this Method}

Today, life is Unimaginable without wireless communications. The technology progress of CMOS (Complementary Metal-Oxide Semiconductor) and small and smaller circuits caused that wireless circuits are used in most electronic instruments. This progress also developed the micro-sensors. These micro-sensors or sensors can perform many senses in some applications as identification of noise for feeling earthquake. In the deserted areas and the places collecting information are not good for human explorations.

Some of the applications of wireless networks are as:

- Objects tracking

- Monitoring vital signs

- Analysis of natural habitat

- Troubleshooting the production line

- Online-game

- Tracking car parking location and etc

The present study applied wireless sensor for locating sensor and vital signs monitoring of the diver.

In recent years, technology progress of telecommunication and industry of micro electric and electronic parts led to the design of small and cheap sensors that are connected via a wireless networks.

These networks are called wireless sensor networks are turned into good instruments to extract data from the surrounding environment and monitoring of environmental events and they are used at home, industry and military operations.

In the design of wireless sensor networks, the main issue is the restricted energy source of sensors. Due to the numerous sensors in the networks or the lack of access to them, changing or charging the battery of sensors is not possible. Thus, presenting some methods for energy optimum consumption that leads to the increase of the life of network is necessary.

The previous researches showed that by organizing network nodes in some clusters, we can achieve high efficiency of the energy. More efficiency of energy leads to the increase of the life of network. In most of the researches, the time until the last node of the network dies is called network life.

In this study, a wireless sensor is used in which nodes clustering is done by genetic algorithm and it is presented by Mohsen Tolu Honari et al. The required network has the following features:

Sensor nodes are all equal and are distributed in all networks in a square-shape area as uniformly.

Telecommunication channel is symmetrical and the model is multi-path.

The nodes all have equal energy and ability.

The situation and location of all the nodes are known in the base station.

Here detailed explanation of these types of sensors is ignored due to having access to them. Later, sensor is defined as the above mentioned sensor.

\section{New Method for Safety of Divers}

In this section, first we present a new approach for safety of divers then we show the advantages of the proposed method by a number of real various cases. When the divers go underwater, besides their equipments they should take a bracelet or watch as followings:

The watch is having the following structures:

The sensor that was explained in the previous section is used here with a plc and screen. This sensor is put in the watch or bracelet of the diver as it is on his pulse. This sensor has special features and in the followings, they are explained by 
some examples.

The diving team should be equipped with sensor and they will be connected through network and critical signs screen is shown on the screen of watch or bracelet. It means that when the vital signs of one of the divers is irregular, red light is observed in the screen of other members and when one of the divers was lost, alarms start and the missed person direct is shown on the screen. A signs screen system being networked with all the sensors should be installed in the boat for the team going underwater from the boat and in coast for those who go underwater from the coast. Thus, a person on the boat or in the coast is informed of the condition of the divers. Also, there is a button on the sensor that divers in critical condition press it to inform other divers in the surface of water.

One of the obvious advantages of this method is its cheapness and simple design. By installing sensors and connecting them with networks, most dangers are reduced.

\subsection{The Advantages of this Design}

The advantages of this instrument are shown by some examples.

Suppose that two professional divers go under water for diving with boat. It is possible that they lose each by some reasons. If they lost each other, they can rotate 360 degree and if they didn't find each other go to the surface and see each other and again if no diver comes up, another diver find that a problem is occurred and from the bubbles on the surface, he relocate the diver underwater. In such situation, if two divers are endangered, one of them faint and anther one is trapped or the diver underwater is out of air and no bubbles come up, in the new instrument, the following conditions are occurred to solve the problem in the shortest time.

1 When two divers separate from each other, alarms start and losing is impossible.

2 If they lose each other, they see the direction on the screen immediately and a person in the boat or in the coast is notified and the diver on the surface of water can get help.

3 When both divers are trapped, the person on the surface of water is informed and he can help.

By this method and introducing it to all countries, we can observe the progress of our economy and by its correct management; we can attain one of the main diving centers in the world.

\section{Conclusion}

Diving is one of the exciting water sport and many people refer for recreation or training to the required centers. Safety and reliable diving are of great importance to dive with comfort and observe the world under water and the glory of our God. The present study introduced the existing sensor and its connection though networks and a new design for safe diving was proposed and then the advantages were presented by some examples.

\section{References}

[1] T. Hajjari, M. Ali Beigi., Research Method, Report and Thesis Writing, Fraranama Publishing (In Persian), 2012.

[2] Akyildiz, I. and Su, W. and Sankarasubramaniam, Y. and Cayirci, E., "A Survey on Sensor Networks", IEEE Communications Magazine, vol 40, Issue 8, pp. 102-114, 2002.

[3] Bachrach, Arthur J. (1988). A PICTORIAL HISTORY OF DIVING, Best Publishing Company, San Pedro, California, USA.

[4] Bagherian, Mohamamd Rasul, 2007. The comprehensive guide of diving in high water. Tehran. Mahsa.

[5] Bagherian, Mohammad Rasul. 2009. The comprehensive guide of advanced diving, Tehran: Pazine.

[6] Ballard RD. Epilogue for Titanic. National Geographic, Vol. 172, October 1987, page 454.

[7] Billings, Henry. (1956). MAN UNDER WATER, Lutterworth Press, London.

[8] Brylske, A., Brief History of Diving, Parts I and II. Dive Training Magazine. August \& September 1994.

[9] Cardone, B, editor. The Fireside Diver. Menasha Ridge Press, Birmingham, 1992.

[10] Carlisle, N., Riches of the Sea. Sterling Publishing Co., New York, 1967.

[11] Cousteau, JY., and Dumas, F., The Silent World. Ballantine Books, New York, 1953.

[12] Cousteau JY, with Dugan J. The Living Sea. Harper \& Row, New York, 1963.

[13] Cousteau, JY., Dugan, J., World Without Sun. Harper \& Row, New York, 1965.

[14] Crichton, M. Spere. Alfred A. Knopf, New York, 1987

[15] Cussler, C., Pacific Vortex. Bantam Books, New York, 1982.

[16] Davis, J., Bikini's Silver Lining. NY Times Magazine, May 1, 1994. Pg. 43.

[17] DeLoach, N., Eagles Fly Alone. aquaCorps N8, 1994; page 65 .

[18] Dugan, J., Man Under the Sea. Harper \& Brothers, New York, 1956.

[19] Dugan, James. (1956). MAN EXPLORES THE SEA, Great Britain, by Hamish Hamilton Ltd, London.

[20] Ellis, RE., The Book of Sharks. Alfred A. Knopf, New York, 1989.

[21] Ellis, RE., McCosker JE. Great White Shark. HarperCollins Publishers, New York, 1991.

[22] Ellis, RE., Monsters of the Sea. Alfred A. Knopf, New York, 1994.

[23] Exley, S., Max Head Room. aquaCorps N7, 1994; pages 64-65. 
[24] Gilliam, B., Von Maier R. History of Diving, in Deep Diving. An Advanced Guide to Physiology, Procedures and Systems. Watersport Publishing, Inc. San Diego; 1992.

[25] Gilpatric, G., The Compleat Goggler. Saturday Evening Post, October 6, 1934, p. 10.

[26] Groves, D., The Oceans. A Book of Questions and Answers. John Wiley \& Sons. New York, 1989.

[27] Guinness Book of Records, Bantam Books, New York. Published annually.

[28] Hamilton, B., Daughtery, G., Kristovich, A., What happened to Sheck Exley? Pressure November/December 1994 (part 1) and January/February 1995 (part 2).

[29] Hamner, WM., Australia's Box Jellyfish. A Killer Down Under National Geographic 86:2, August, 1994; p. 116.

[30] Heinzelman, W., Chandrakasan, A., and Balakrishnan, H., "An Application-Specific Protocol Architecture for Wireless Microsensor Networks", IEEE Transactions on Wireless Communications, vol. 1, no. 4, pp. 660-670, 2002.

[31] Hendrickson, R., The Ocean Almanac. Doubleday, New York, 1984.

[32] Hong, et. al. Daily diving pattern of Korean and Japanese breath-hold divers (ama). Undersea Biomedical Research 1991;18:433-443.

[33] Holliday, L., Coral Reefs. Tetra Press, Morris Plains, NJ, 1989.

[34] Huehner, JC., The Call of the Deep. The Cleveland Plain Dealer, August 2, 1994, page 1.

[35] Leaney, L., The Mark V Column. Historical Diver, No. 2, Winter 1993; p. 17.

[36] Madsen, A., Cousteau. An Unauthorized Biography. Beaufort Books Publishers, New York, 1986.

[37] Manion, DJ., IANTD Journal, 9628 N.E. 2nd Avenue, Suite D, Miami Shores, Florida 33138-2767; issue of May-July 1994, page 8 .

[38] Martin, M., Porter M. Video Movie Guide 1995. Ballantine Books, New York, 1994.

[39] Marx, RF, with Marx, J., The Search for Sunken Treasure. Exploring the World's Great Shipwrecks. Key-Porter Books, Toronto, 1993.

[40] Marx, RF., Into the Deep. Van Nostrand Reinhold, New York, 1978.
[41] Marx, RF., The History of Underwater Exploration. Dover Publications, Inc., New York, 1990.

[42] McCullough, D., The Great Bridge. The Epic Story of the Building of the Brooklyn Bridge. Simon and Schuster, New York, 1972.

[43] Munson, R., Cousteau: the Captain and His World. Wm. Morrow \& Co., New York, 1989.

[44] Nichols, G., History of Diving, in Alert Diver, Divers Alert Network, May/June 1993.

[45] Protasio, J., To the Bottom of the Sea. True Accounts of Major Ship Disasters. Carol Publishing Group, New York, 1990.

[46] Roessler, C., Underwater Wilderness: Life Around the Great Reefs. Chanticleer Press, New York, 1986.

[47] Sammon, R., Seven Underwater Wonders of the World. Thomasson-Grant, Inc. Charlottesville, VA, 1992.

[48] Sheard, B., Beyond Sport Diving! Exploring the Deepwater Shipwrecks of the Atlantic. Menasha Ridge Press, Birmingham, AL, 1991.

[49] Sterba, JP., Klutzy Scuba Divers Love the Coral Reefs A Bit Too Vigorously. Wall Street Journal, May 7, 1993. Page 1.

[50] Talyor, MR., Deep, Dark and Deadly. The perils of cave diving didn't spare even the sport's greatest star. Sports Illustrated, Vol 81, No. 14, October 3, 1994.

[51] Toluhonari, Mohsen; Tashtarian, Farzad; Chitizade, Jalil; Rajabi Mashhadi, Habib. 2007. Nodes clustering in wireless sensor networks by genetic algorithm, The first common congress of fuzzy systems and intelligent systems. Ferdoosi University of Mashhad. Mashhad. Iran.

[52] Verne, J., 20,000 Leagues Under the Sea. 1925; Charles Scribner's Sons, New York

[53] Whittingham. The Rand McNally Almanac of Adventure. Rand McNally,Chicago, 1982.

[54] Younis, O., Krunz, M. and Ramasubramanian, S., "Node clustering in wireless sensor networks: recent developments and deployment challenges", Network, IEEE, vol 20, Issue 3, pp. 20 - 25, May-June, 2006.

[55] Zumrick, J., Sheck Exley: Preliminary Accident Report. aquaCorps N8, 994; page 71. 